\title{
Protocol
}

\section{Assessment of the feasibility and potential effectiveness of a baby- friendly workplace support initiative in rural Kenya: a study protocol}

\author{
Elizabeth W. Kimani-Murage ${ }^{1}$, Teresia N. Macharia ${ }^{1}$, Eva W. Kamande ${ }^{1 *}$, Peter M. Gatheru ${ }^{1}$, \\ Hermann P. P. Donfouet ${ }^{1}$, Taddese Alemu' ${ }^{1}$, Laura Kiige ${ }^{2}$, Susan Jobando ${ }^{2}$, Lynette A. Dinga ${ }^{2}$, \\ Betty Samburu ${ }^{3}$, Joyce Atinda ${ }^{3}$, Samuel Watson ${ }^{4}$, Claudia Mitchell ${ }^{5}$, Paula Griffiths ${ }^{6}$, \\ Richard Lilford ${ }^{4}$, Debra Jackson ${ }^{7}$, France Begin ${ }^{7}$, Grainne Moloney ${ }^{2}$
}

\author{
${ }^{1}$ African Population and Health Research Center, Kenya \\ ${ }^{2}$ UNICEF Country Office, Kenya \\ ${ }^{3}$ Ministry of Health, Unit of Nutrition and Dietetics, Kenya \\ ${ }^{4}$ University of Warwick, UK \\ ${ }^{5}$ McGill University, Canada \\ ${ }^{6}$ Loughborough University, UK \\ ${ }^{7}$ UNICEF Headquarter, USA
}

Received: 26 August 2020

Revised: 16 December 2020

Accepted: 06 January 2021

\section{*Correspondence:}

Dr. Eva W. Kamande,

E-mail: eva.kamande@gmail.com

Copyright: () the author(s), publisher and licensee Medip Academy. This is an open-access article distributed under the terms of the Creative Commons Attribution Non-Commercial License, which permits unrestricted non-commercial use, distribution, and reproduction in any medium, provided the original work is properly cited.

\section{ABSTRACT}

Background: Employment poses a barrier in achieving the World Health Organization's recommendation of exclusive breastfeeding for the first six months of life. Effective strategies and evidence to improve breastfeeding for women working in the agricultural sector - the main employer for women in Kenya - is lacking. This study aimed to inform (with evidence) the design and implementation of a scalable model of workplace support for breastfeeding in an agricultural setting in Kenya; as well as investigated the model's potential operational feasibility and potential effectiveness, and its cost-effectiveness.

Methods: The study employed a mixed methods approach and participatory methods at the pre-implementation, implementation and post-implementation phases. The pre-implementation phase generated evidence to inform the implementation. Mothers with children under 12 months were interviewed at the pre-implementation (2016) and postimplementation (2018) phase. Managers, supervisors, decision and policy makers, as well as other community members were also targeted. Statistical methods will include analysis of covariance and logistic regression. Additionally, costeffectiveness and cost-benefit analyses will be done. Qualitative data will be analysed in vivo, using thematic analysis technique.

Conclusions: Findings from this study aimed to inform the potential feasibility and potential effectiveness of a babyfriendly workplace support for breastfeeding initiative in an agricultural setting with a goal of improving child nutrition and health. The findings also contribute to policy and practice in Kenya by informing the development of workplace support guidelines.

Trial Registration: ISRCTN registry, ISRCTN 64692465; date of registration: 21 December 2016 - retrospectively registered, http://www.isrctn.com/ISRCTN64692465.

Keywords: Breastfeeding, Workplace support, Plantation, Kenya 


\section{INTRODUCTION}

Breastfeeding provides a child with the best start to life, and is the most effective preventive health measure for mother and child. Not exclusive breastfeeding in the first six months of life has been associated with higher morbidity and mortality compared to exclusive breastfeeding (EBF). ${ }^{1-2}$ Evidence indicates that breastfeeding in childhood is associated with higher intelligence quotient levels, educational attainment, and income in adulthood. In addition, it has greater protection against type 2 diabetes, breast and ovarian cancer, and improves birth spacing among women. ${ }^{4}$

In 2003, the World Health Organization (WHO), stipulated guidelines on infant and young child feeding practices to promote healthy growth and development of children and reduce the incidence of under-nutrition. ${ }^{5,6}$ The guidelines recommend that all infants should be put to the breast within an hour after birth and breastfed exclusively for the first six months of life. Thereafter introduce nutritionally adequate and safe foods that complement breast milk, with continued breastfeeding for two years and beyond. ${ }^{6}$ Statistics show poor adherence to the WHO breastfeeding guidelines. In 2014, the global and sub-Saharan African EBF rates were at $38 \%$ and $36 \%$ respectively. This was significantly lower than the World Health Assembly 2025 global target of increasing EBF rates to at least $50 \%$ and the recommended WHO coverage target of $90 \% .^{7}$

In Kenya, the National Nutrition Action Plan 2012-2017 mainstreams the promotion of EBF as one of the priority nutrition interventions in the country. ${ }^{8}$ While there has been significant improvement in EBF rates from $32 \%$ in 2008 to $61.4 \%$ in 2014 , children are still being suboptimally breastfed due to different factors. ${ }^{9}$ One such factor is the persistent barrier posed by maternal employment which impedes a mother's ability to optimally continue breastfeeding. ${ }^{10-14}$ The EBF rate among employed mothers rapidly declines after their return to work. Mainly due to the lack of breastfeeding breaks, inadequate facilities for pumping and storing milk, lack of resources to promote breastfeeding, and lack of support from employers and colleagues for employed mothers who desire to continue breastfeeding by expressing their milk in the workplace. ${ }^{14} \mathrm{~A}$ study in Sydney by Weber et al found that returning to work was one of the main reasons women stopped breastfeeding. While $60 \%$ of women intended to continue breastfeeding when they returned to work, only $40 \%$ were doing so. ${ }^{15}$

The baby-friendly workplace initiative (BFWI) was launched during the 1993 breastfeeding week to focus on combining women's work and breastfeeding. The objective was to complement the baby-friendly hospital initiative and extend baby-friendliness beyond the hospital walls and into women's working environments. Since then, numerous advocates worldwide used the concept to raise awareness about breastfeeding and the rights and needs of working breastfeeding women calling upon various actors to play their respective roles to promote breastfeeding at the workplace.

In Kenya, $62 \%$ of women are in the workforce, many in the informal sector. Forced by the need to provide income for their families and driven by the fear of losing their jobs, over $50 \%$ of mothers return to work within three months after birth. $^{16,17}$ The pressure to work long hours, the inability to maintain a work-life balance, and lack of support at the workplace are some of the factors that reduce breastfeeding rates among working mothers. Moreover, the three months maternity leave provided in the current Kenya Employment Act is not sufficient to support EBF in the first six months. The fact that threequarters of the population in many African societies, including Kenya, work informally, also means that maternity leave policies hardly serve the majority of mothers, especially those in lower income groups. ${ }^{18}$ In addition, women in urban poor settings in Kenya resume work too soon after delivery and work for long hours which leaves them unable to breastfeed optimally as they are not allowed to bring their children to work. ${ }^{19}$ Necessitating the need to promote breastfeeding-friendly workplaces for employed mothers in order to increase the duration of breastfeeding. ${ }^{20-22}$ Provision of workplace support is important for continued breastfeeding, particularly in Kenya's agricultural sector which is a key employer for women: approximately $60 \%$ of workers in crop plantations are women. ${ }^{23}$ Poor working conditions and access to health services for workers in the agricultural sector has been documented, although this varies by farm product. ${ }^{24}$ Workers in flower farms receive higher pay, better contracts and greater job security in comparison to their counterparts in the fruit, vegetable and tea farms. ${ }^{25}$

According to the HER project, women who work in the agricultural export sector have limited exposure and accessibility to community-based health education programs. In addition, increased knowledge on maternal health, nutrition and hygiene enhances wellbeing of the employees while reducing health-related absenteeism. ${ }^{25}$ As women comprise a large proportion of workers in plantations, it is important to understand the conditions that are necessary to support an enabling environment for breastfeeding in the workplace.

Through this study, we aimed to inform (with evidence) the design and implementation of a scalable model of workplace support for breastfeeding in an agricultural plantation in Kenya's Kericho County. In addition, we investigated the model's potential operational feasibility and potential effectiveness, as well as its costeffectiveness. The primary objective was to examine the potential feasibility, acceptability, and uptake of a new model on workplace support for breastfeeding in a Kenyan agricultural plantation. Secondary objectives included: establishing the prevailing workplace and living environment of plantation workers with regards to breastfeeding and infant feeding practices, child nutrition, 
and healthcare practices; determine the potential effectiveness of the workplace support initiative on work participation and productivity of female workers; breastfeeding and infant feeding practices; and, child nutritional and health status; determine the cost and the potential cost-effectiveness of the workplace support initiative, and health benefits for employees and their children; and, to determine the implications for learning from the research for policy, programming and scaling, and future research.

We used the conceptual framework developed by Hector et al that proposed three factors (Figure 1) that influence breastfeeding practices. ${ }^{26}$ These factors include: individual level factors that directly influence mother, child, and the 'mother-child' dyad; group level factors which constitute the attributes of the environments where the mother and child live and which enable the mother to breastfeed; and the society level factors, which influence the acceptability and expectations regarding breastfeeding and provide the context for breastfeeding. Our focus was mainly on the work environment, under the group level factors, in which policies, practices, and facilities that influence a mother's ability to combine work and breastfeeding were addressed. The study also investigated mothers' intentions to breastfeed, their knowledge and skills. In this study, we blended the potential effectiveness of a community based intervention with gathering information on implementation challenges and facilitators (feasibility). We used this approach as it is known to speed up knowledge creation and increase the usefulness and policy relevance of implementation research. It also supports more rapid translational gains in intervention uptake, more effective implementation strategies, and more useful information for researchers and decision makers. ${ }^{27,28}$ Findings from this study will inform further research and efforts that seek to promote, support and protect breastfeeding at work, consequently lead to an increased number of baby-friendly workplaces in agricultural labor settings where the greater percentage of employees are women employed on a casual basis.

\section{METHODS}

\section{Study setting}

The study was conducted in a plantation in Kericho County, located in the highlands to the west of the Kenyan Rift valley. The county covers an area of $2,111 \mathrm{~km}^{2}$ and is home to some of the largest tea companies. It has a population of $739,872,44 \%$ within the $0-14$ age bracket while $42 \%$ of the households have 4-6 members. The total fertility rate is 4 children per woman. ${ }^{9}$ The study site covers over 8,700 hectares and has a population of over 80,000 people in 112 villages. There are close to 16,000 employees, a third being women. Majority of the employees are seasonal workers, working as tea pickers. The minority are permanent employees working within the factories, offices, and as security personnel. There is an organized healthcare system supported by the employer, that is, one major hospital (level 4), four health centers (level 3), and 23 dispensaries (level 2), as well as comprehensive HIV/AIDS programs. Social facilities include staff houses, social halls, schools (20 primary schools, eight secondary schools and 53 early childhood development centers), clean water and electricity supply. The plantation has peer educators who work as volunteers for health and social matters.

\section{Study population}

The study mainly focused on female employees (permanent and seasonal), specifically women of reproductive age (15-49 years) with infants younger than 12 months old, and the infants themselves. Male employees and other community members like fathers, grandmothers, and community leaders were also interviewed. Also interviewed were the plantation managers, supervisors, healthcare workers, and policy and decision makers at local and national level. While conducting the research, we excluded eligible participants who had physical or intellectual impairments that could hinder clear communication e.g. deaf participants. However, they were not excluded from the intervention.

\section{Study design}

We employed a pre-post study designed into a preimplementation, mid-line and post-implementation phase (Figure 2), where qualitative and quantitative data collection methods were used. The study was an evaluation and an implementation research project in line with the WHO's alliance for health policy and systems research (WHO/AHPSR) implementation research guide (http://bit.ly/1Nr3S1Q) and the 2010 quality standards for development of evaluation by the organization for economic co-operation and development/development assistance committee (OECD/DAC). ${ }^{29}$ To answer the research questions adequately, we employed quantitative and qualitative approaches by combining effectivenessimplementation hybrid trials and participatory action research methods as described in the WHO/AHPSR implementation research guide. The purpose of the effectiveness-implementation hybrid trials is to combine elements of implementation research and potential effect, which will help to assess both the implementation strategy and the potential effectiveness of the initiative. In this study, the participatory action research included innovative participatory methods such as photovoice and participatory videos that encouraged involvement of beneficiaries and co-ownership of the initiatives enhancing transparency, accountability and capacity building. Photovoice is an innovative participatory engagement method for facilitating group involvement. The group generates photographic work that captures their lived experiences while participatory video is an approach where a community or small group creates their own videos in relation to critical issues in their lives. This gives the community a chance to explore issues, voice their 
problems, and come up with solutions through creative stories.

The main purpose of the pre-implementation phase was to generate evidence to assess the potential effectiveness of the intervention, generate learning to inform implementation of the initiative and tailor the intervention to the context in which it was applied to. This phase took place between September and November 2016 and included a baseline survey involving mothers with children aged less than 12 months old. Also conducted in this phase was a community readiness assessment (https://bit.ly/2zHkLsW) i.e. the degree to which a community is ready to take action on an issue, helping women to successfully combine breastfeeding and work. The community readiness model was used to identify the dimensions and levels of community readiness. It integrates a community's culture, resources, and level of readiness for a proposed intervention. It also comprises an instrument for determining community readiness. Readiness can range from none at all to already having successful programs in place. This helped to target and tailor the intervention to the appropriate level of community readiness. The data generated in the preimplementation phase was used to develop the intervention in the period between December 2016 and April 2017.

The study was implemented for a period of 12 months, May 2017 to April 2018, in three purposively selected intervention sites. In line with the principles of BFWI, the intervention consisted of three essential and integrated activities that aimed to ensure that every mother, regardless of whether she is formally employed or not, can combine breastfeeding and work successfully. The three essential intervention activities were related to the following: time - paid maternity leave for three months, flexible working hours and breastfeeding breaks for at least 30 minutes; space/proximity - provide infant care at or near the workplace, through establishment of day care centers for expressing and storing breast milk within a clean and non-hazardous work environment; support and home-based counselling - every mother included in the study was provided with support like maternity benefits, job security, supportive attitudes towards breastfeeding in public, networks of supportive women in unions and worker groups, in addition, home-based counselling on issues related to breastfeeding and infant feeding was given to every mother and other community members through trained community counselors.

The process evaluation aimed to document process indicators during the implementation phase. The implementation period was adequate to impact the duration of EBF (which was our primary outcome) and provide an indication of its potential effect on other outcomes including work participation, productivity, nutritional and health outcomes of the infants. The information gathered during this phase was useful in the implementation phase and in engaging the stakeholders including the plantation managers, Ministry of Health, and UNICEF representatives. This phase was conducted by observing improvements in community workplace conditions and support for breastfeeding. Checklists were developed using referenced guidelines, and data obtained from monthly records on work participation and productivity for breastfeeding women. Utilization by women of community workplace support provisions put in place during the implementation phase were also monitored. Six months after the beginning of the intervention phase, mid-line qualitative interviews were conducted. The end of the implementation phase was marked by a post-implementation phase where recruitment of all mothers with children under 12 months was done and end-line data collected. The group was independent of the baseline survey group, any overlap was coincidental rather than planned. The post-implementation survey was conducted between May and July 2018 and aimed to assess experiences and potential effects of the intervention. To ensure comparability and to determine the potential effectiveness of the intervention, the same tools (including the checklist) were used.

\section{Sample size}

\section{Quantitative study}

The ultimate objective of the study was to increase EBF in the plantation. An estimated sample size of 600 women (300 women at baseline and 300 at end-line) was determined to have adequate power to detect an increase in EBF from $17 \%$ (the proportion of women practicing EBF in Kericho County), to $27 \%$ after 12 months of the intervention. ${ }^{30}$ We used a $5 \%$ level of precision, $95 \%$ confidence interval, a power of $80 \%$ (leading to an effect size [E.S.] of 0.241), and adjusted the sample size with the non-response rate of $10 \%$, hence the estimated sample size of 300 women at baseline and at end-line.

It was estimated that there are about 720 births in the study area every year (personal communication with the plantation management). We therefore recruited all the women with children less than 12 months old to allow for subgroup analyses (e.g. seasonal versus permanently employed), which we expected to be about \pm 720 for the baseline and end-line surveys.

\section{Qualitative study}

Purposive sampling was used to select the participants in the three aforementioned study phases. Focus group discussions (FGDs; $n=12$ ), in-depth interviews (IDIs; $n=8$ ) and key informant interviews (KIIs; $n=24$ ) were planned. The sample size was 80-100 participants, however, the number of interviews per study and sub-group mainly depended on the level at which saturation of concepts was achieved.

In the community readiness assessment, a total of eight-10 purposely selected participants were interviewed. 


\section{Assessment}

\section{Primary outcome}

The primary outcome was the duration of EBF during the first six months. We anticipated that the proposed intervention will lead to potential change in breastfeeding practices, subsequently improving EBF and demonstrating adherence to the WHO breastfeeding guidelines. Data was collected at baseline and then regularly from the first month post-delivery, until the end of the implementation. Analysis focused on the difference in the proportion of infants exclusively breastfeeding between the baseline and end-line surveys.

\section{Secondary outcomes}

\section{Quantitative}

Nutritional status of infants: We anticipated that the intervention will have a potential effect on the nutritional status of infants. Anthropometric measures: height, weight, and mid-upper arm circumference measurements of children under 12 months old was taken where applicable. The measurements were collected by research assistants using standard procedures. ${ }^{31}$ The measures were collected at baseline and during the intervention period. We used the WHO 2006 growth standards to generate the weight-for-age $\mathrm{Z}$-scores, height-for-age $\mathrm{Z}$-scores and weight-for-height $\mathrm{z}$-scores. ${ }^{32}$ These measures helped assess whether the child was stunted, wasted or underweight.

Morbidity in children and health-seeking behaviors: Breastfeeding is a preventive health measure against childhood preventable illnesses. We expected that the intervention will potentially have an effect on the morbidity of children and health-seeking behaviors. Morbidity was assessed using 14-day recall. Data was collected at baseline, during the intervention and at endline through mothers' self-reporting and interviewer administered questionnaires.

Breastfeeding knowledge, attitudes and practices : They were accessed according to the WHO recommendations on breastfeeding. ${ }^{6}$ This included timing and initiation of breastfeeding including breast milk expression, continued breastfeeding with complementary feeding of infants assessed using 24-hour recall. Data was collected through mothers' self-reporting using an interviewer administered questionnaire at baseline, implementation and end-line to determine change in knowledge, attitudes and practices brought about by the intervention.

\section{Potential effect of the intervention on work participation and productivity}

The effect of employed women was measured using a presenteeism and absenteeism scoring method. This was collected at baseline and end-line through self-reporting by mothers and the employer; observations of changes in community workplace conditions and support; references to guidelines using checklists; and obtaining records on work participation and productivity for breastfeeding women.

\section{Qualitative}

We conducted pre-intervention, mid-line and postintervention qualitative studies with the intention to assess: community readiness to assess the degree to which community members were willing to support mothers in successfully combining breastfeeding with work; prevailing workplace conditions, perceived effects on health and wellbeing, work participation and employee productivity, breastfeeding practices and aspirations for change; enabling factors and limitations of workplace support, its importance and benefits, acceptability and readiness for improvement, as well as feasibility during implementation were collected using the above qualitative methods targeting the same participants; and satisfaction, potential areas for improvement and adaptation of the initiative.

\section{Data collection and analysis}

Data collectors for the quantitative and qualitative survey were graduates in public health, nutrition, and social sciences with field experience. Trainees underwent one week of training covering project objectives, research ethics, procedures for seeking informed consent, and a comprehensive review of the data collection tools. The training also included demonstrations of interviewing techniques through role-plays and group discussions. The supervisors received additional training in management of data collection, team dynamics, survey planning and logistics, observing interviews, and conducting spot checks for data quality. Role plays were highly emphasized in order for trainees to practice, grasp the project objectives, and understand the instruments. Piloting of the instruments was done to ensure the tools captured the information expected. Thereafter, debriefing sessions with the interviewers were held to share field experiences and address emerging issues.

The quantitative survey was conducted electronically using a smartphone onto which an intervieweradministered questionnaire was programmed and administered by the trained research assistants. To ensure data quality, validation checks were embedded in the software during the development and programmed so as not to allow missing data and implausible out of range values. The quality control team further tested the tools to ensure consistency and flow of questions before the tools were implemented. To verify the authenticity of the quantitative data, data quality checks were regularly conducted through spot checks and sit-ins for $10 \%$ of each research assistant's daily work. A discrepancy report was then generated to help follow up inconsistencies or errors in the data. An automated routine check on the data 
completeness, correctness and consistency was also run on $100 \%$ of the collected data. Data was synchronized with a master database after each data collection activity.

\section{Quantitative data collection}

Quantitative data was collected from breastfeeding mothers and the employer. In the process evaluation, quantitative data was collected from the women recruited at baseline within the first month post-delivery, continued monthly until the child was six months old, and regularly thereafter until the end of the implementation. We also monitored utilization of community workplace support provisions. To ensure comparability and to determine the potential effect of the intervention, the same tools and participants interviewed at baseline survey were interviewed during the end-line survey.

\section{Innovative participatory action research methods}

We employed photovoice and participatory videos to document the community workplace environment, conditions and experiences of women and community members. The research team grouped the participants into small groups and briefed them on the project objectives, ethics and informed consent procedures. Ethics in photovoice involve not capturing faces or any identifiable detail in photos but in participatory videos it is not possible to apply the no-face technique or anonymization. Group members were given a prompt that was answered through generation of photos and creating videos which captured, through their own eyes, critical experiences. This gave the community a chance to explore issues, voice their problems, and come up with solutions through creative stories. It also encouraged community involvement, coownership of the initiative as well as enhanced their capacity to document knowledge/information through audio-visual methods. Follow-up tape-recorded qualitative sessions were held to discuss the photos and videos generated in order to assess the knowledge base, practices and perceptions on breastfeeding, breast milk expression, and the challenges and opportunities for breastfeeding mothers working in the plantation.

\section{Qualitative data collection}

The FGD and IDI discussions were conducted with eligible women who were either pregnant or had children aged less than one year. Also interviewed were spouses and other men working in the plantation, and peer educators. The village elders and the employer helped identify all participants. Key informants were selected based on their social standing and knowledge of the subject. They included the employer, local leaders and healthcare workers (doctors, nurses and nutritionists) serving the plantation. Also included were stakeholders from the Ministry of Health, county government, local community leaders, UNICEF and, members of the Kenya Private Sector Alliance (KEPSA).
The community readiness assessment included: selecting four to 10 people to interview, these were people who knew the community and who would reflect the perceptions of the various stakeholders including the community members, leaders, the County Health Management Team, the County Government and the employer; contacting the people identified and inviting them to participate, each interview took 30-60 minutes; conducting the interviews which were recorded and notes taken; and scoring the interviews to determine the dimension and overall readiness scores.

All tape recorded qualitative interviews were transcribed verbatim to ensure accuracy. Transcribed files were saved in word format. The quantitative and qualitative approaches are outlined in Table 1.

\section{Data analysis}

Data analysis is currently ongoing. Table 2 presents a detailed data analysis plan.

Qualitative data analysis: Transcribed data, including those from photovoice and participatory videos, will be coded in vivo (QSR International Pty Ltd., Burlington, MA, USA) to identify primary and meta-codes, as well as major themes. We will use thematic framework analysis and base our analysis on existing and well known theories from the literature to organize themes. Themes will be identified focusing on contradictions and diversity of experiences as well as perception and attitudes among the different stakeholders. Analysis across all transcripts will be done thematically.

Quantitative data analysis: To evaluate the feasibility of the intervention, analysis will involve comparison of the primary outcome (EBF) and secondary outcomes (nutritional status of infants, breastfeeding practices, children's morbidity, work participation and productivity) at baseline and end-line. Relevant statistical tests including, but not limited to t-test, ANOVA and chi-square tests will be run for comparison of baseline and end-line results of key variables. Regression analysis will be run to determine probability of EBF with confidence intervals (CI) and identify predictors of success for primary outcome $(\mathrm{EBF})$. Potential confounders attributable to baseline differences such as food security and socioeconomic status, will be controlled using a logbinomial model.

Probit and logit specifications will be compared for goodness of fit using the Watanabe Akaike Information criterion (WAIC). The outcome will be EBF. Covariates included in the model will be a binary variable indicating pre- and post-intervention period, parity, mother's education, anthropometry including height and weight, mother's age, household income, and self-reported health.

Analysis will predominantly be done using STATA version 13 (StataCorp. 2013. Stata Statistical Software: Release 13. College Station, TX: StataCorp LP). 
Table 1: Quantitative and qualitative data collection procedures.

\begin{tabular}{|c|c|c|}
\hline Study objective & Variable/data & $\begin{array}{l}\text { Data collection } \\
\text { method/participants }\end{array}$ \\
\hline \multicolumn{3}{|l|}{$\begin{array}{l}\text { Pre-implementation } \\
\text { phase }\end{array}$} \\
\hline \multirow{10}{*}{$\begin{array}{l}\text { To establish the prevailing } \\
\text { workplace and living } \\
\text { environment of plantation } \\
\text { workers with regard to } \\
\text { breastfeeding and infant } \\
\text { feeding practices, child } \\
\text { nutrition and healthcare } \\
\text { practices }\end{array}$} & $\begin{array}{l}\text { Breastfeeding practices including EBF for six months } \\
\text { and child feeding practices using } 24 \text {-hour recall }\end{array}$ & Quantitative \\
\hline & $\begin{array}{l}\text { Nutritional and health status of children using } \\
\text { anthropometry and mother-reported morbidity using } \\
\text { 14-day recall }\end{array}$ & $\begin{array}{l}\text { Mothers with children under } 12 \\
\text { months, managers and } \\
\text { supervisors }\end{array}$ \\
\hline & Experiences with current workplace support & Qualitative \\
\hline & $\begin{array}{l}\text { Work participation and productivity including } \\
\text { presenteeism and absenteeism }\end{array}$ & $\begin{array}{l}\text { Community readiness } \\
\text { assessment }\end{array}$ \\
\hline & $\begin{array}{l}\text { Caregiver's health-seeking behaviors including } \\
\text { pregnancy history, antenatal care }\end{array}$ & $\begin{array}{l}\text { FGDs, with men (fathers), } \\
\text { mothers, peer educators and } \\
\text { other community member's e.g. } \\
\text { grandmothers }\end{array}$ \\
\hline & $\begin{array}{l}\text { Data on water and sanitation, hygiene and food } \\
\text { security }\end{array}$ & IDIs with mothers and fathers \\
\hline & $\begin{array}{l}\text { Data based on the national guidelines and policies for } \\
\text { supporting breastfeeding in the workplace to assess: } \\
\text { provisions for maternity leave, breastfeeding breaks } \\
\text { and/or flexi-time for breastfeeding mothers; } \\
\text { provisions for appropriate space and facilities to } \\
\text { support breastfeeding mothers at the workplace } \\
\text { including breastfeeding rooms; and provisions for } \\
\text { other support at the workplace including sensitization } \\
\text { of workers and supportive policies that enable } \\
\text { breastfeeding mothers to successfully return to work. }\end{array}$ & $\begin{array}{l}\text { KIIs with health professionals } \\
\text { (doctors, nurses and } \\
\text { nutritionists), policy and } \\
\text { decision makers including } \\
\text { national and county health } \\
\text { managers, plantation managers } \\
\text { and supervisors }\end{array}$ \\
\hline & $\begin{array}{l}\text { Current workplace environment, perceived potential } \\
\text { effect on health and wellbeing, work participation } \\
\text { and productivity of the workers, current practices } \\
\text { including breastfeeding and aspirations for change }\end{array}$ & \multirow{3}{*}{$\begin{array}{l}\text { Photovoice and participatory } \\
\text { videos with mothers and peer } \\
\text { educators }\end{array}$} \\
\hline & $\begin{array}{l}\text { Understanding of workplace support and perceptions } \\
\text { of its importance, anticipation, acceptability and } \\
\text { readiness for improvement including anticipated risks } \\
\text { and benefits, feasibility including facilitating and } \\
\text { limiting factors in the implementation of the initiative }\end{array}$ & \\
\hline & $\begin{array}{l}\text { Recommendations for adaptation of the initiative and } \\
\text { participants' perceived roles }\end{array}$ & \\
\hline \multicolumn{3}{|l|}{ Implementation phase } \\
\hline \multirow{6}{*}{$\begin{array}{l}\text { To assess the potential } \\
\text { feasibility, acceptance, } \\
\text { and uptake of a new } \\
\text { model on workplace } \\
\text { support for breastfeeding } \\
\text { in a Kenyan agricultural } \\
\text { plantation }\end{array}$} & $\begin{array}{l}\text { Experience with workplace support, satisfaction and } \\
\text { potential areas of improvement }\end{array}$ & Qualitative \\
\hline & $\begin{array}{l}\text { Breastfeeding practices and work participation within } \\
\text { the first month after delivery and every month } \\
\text { thereafter until the child is six months old using } 24- \\
\text { hour recall }\end{array}$ & $\begin{array}{l}\text { FGDs and IDIs with mothers } \\
\text { and other beneficiaries }\end{array}$ \\
\hline & Infant feeding practices after six months & $\begin{array}{l}\text { KIIs with implementers, } \\
\text { counsellors, plantation managers } \\
\text { and supervisors }\end{array}$ \\
\hline & $\begin{array}{l}\text { Nutritional and health status of children using } \\
\text { anthropometry and mothers' self-reported morbidity } \\
\text { using 14-day recall }\end{array}$ & $\begin{array}{l}\text { Quantitative methods with } \\
\text { mothers }\end{array}$ \\
\hline & \multirow[b]{2}{*}{ Mothers' healthcare-seeking behavior } & $\begin{array}{l}\text { Obtain monthly records on work } \\
\text { participation }\end{array}$ \\
\hline & & $\begin{array}{l}\text { Monitor utilization by the } \\
\text { women of community workplace } \\
\text { support provision. }\end{array}$ \\
\hline
\end{tabular}




\begin{tabular}{|c|c|c|}
\hline Study objective & Variable/data & $\begin{array}{l}\text { Data collection } \\
\text { method/participants }\end{array}$ \\
\hline \multicolumn{3}{|l|}{ Post-implementation phase } \\
\hline \multirow{7}{*}{$\begin{array}{l}\text { To determine the potential } \\
\text { effectiveness of the } \\
\text { workplace support } \\
\text { initiative on work } \\
\text { participation and } \\
\text { productivity of female } \\
\text { workers; breastfeeding } \\
\text { and infant feeding } \\
\text { practices; and, child } \\
\text { nutritional and health } \\
\text { status }\end{array}$} & $\begin{array}{l}\text { Breastfeeding practices including EBF for six months } \\
\text { and child feeding practices using 24-hour recall }\end{array}$ & $\begin{array}{l}\text { Quantitative with mothers and } \\
\text { employer }\end{array}$ \\
\hline & $\begin{array}{l}\text { Nutritional and health status of children using } \\
\text { anthropometry and mother reported morbidity using } \\
\text { 14-day recall }\end{array}$ & Qualitative \\
\hline & $\begin{array}{l}\text { Experiences with current workplace support, } \\
\text { satisfaction and potential effect of the intervention on } \\
\text { their wellbeing and that of their family }\end{array}$ & $\begin{array}{l}\text { FGDs with men (fathers), } \\
\text { mothers, peer educators and } \\
\text { other community member's e.g. } \\
\text { grandmothers }\end{array}$ \\
\hline & $\begin{array}{l}\text { Work participation and productivity including } \\
\text { presenteeism and absenteeism/work cessation during } \\
\text { the implementation period }\end{array}$ & IDIs with mothers and fathers \\
\hline & Mothers healthcare-seeking behaviors & $\begin{array}{l}\text { KIIs with health professionals } \\
\text { (doctors, nurses and } \\
\text { nutritionists), policy and } \\
\text { decision makers including } \\
\text { national and county health } \\
\text { managers, plantation managers } \\
\text { and supervisors }\end{array}$ \\
\hline & \multirow{2}{*}{$\begin{array}{l}\text { Experiences and satisfaction with the community } \\
\text { workplace support; potential areas for improvement; } \\
\text { workplace conditions; observed changes and } \\
\text { perceived potential effect on work participation; } \\
\text { productivity including absenteeism and work } \\
\text { cessation during the implementation phase; } \\
\text { breastfeeding practices including EBF for six months } \\
\text { and extended breastfeeding; other child care practices } \\
\text { and nutritional and health status of children; health } \\
\text { and wellbeing of women and their families }\end{array}$} & $\begin{array}{l}\text { Photovoice and participatory } \\
\text { videos with mothers and peer } \\
\text { educators }\end{array}$ \\
\hline & & Observation checklist \\
\hline \multirow{4}{*}{$\begin{array}{l}\text { To assess the cost- } \\
\text { effectiveness of the } \\
\text { workplace support } \\
\text { initiative, and health } \\
\text { benefits for employees } \\
\text { and their children. } \\
\text { Furthermore, we will } \\
\text { conduct a cost-benefit } \\
\text { analysis on the business } \\
\text { impacts for the employer }\end{array}$} & $\begin{array}{l}\text { Average differences in productivity and days in work } \\
\text { will be estimated }\end{array}$ & $\begin{array}{l}\text { Examine the employer's } \\
\text { perspective and determine the } \\
\text { return on investment by } \\
\text { considering the costs to the } \\
\text { business of implementing the } \\
\text { intervention and using the data } \\
\text { captured in the surveys on } \\
\text { worker absenteeism and } \\
\text { productivity }\end{array}$ \\
\hline & $\begin{array}{l}\text { The potential changes in the labor force such as } \\
\text { retention of high performing staff, maintenance of a } \\
\text { skilled workforce, improved morale, motivation and } \\
\text { reputational benefit will be estimated from the } \\
\text { quantitative interviews }\end{array}$ & $\begin{array}{l}\text { Estimate the cost effectiveness } \\
\text { of the intervention in terms of } \\
\text { cost per disability adjusted life } \\
\text { years (DALYs) }\end{array}$ \\
\hline & $\begin{array}{l}\text { Healthcare utilization will also be accounted for as } \\
\text { this is provided by the employer }\end{array}$ & $\begin{array}{l}\text { Healthcare costs, utilization and } \\
\text { the DALYs associated with the } \\
\text { observed change in } \\
\text { breastfeeding rates will be } \\
\text { identified from the literature }\end{array}$ \\
\hline & & $\begin{array}{l}\text { Business case model will also be } \\
\text { developed using cost-benefit } \\
\text { analysis. We will develop a net- } \\
\text { cost model to estimate the } \\
\text { substantial cost savings using } \\
\text { the productivity approach. }\end{array}$ \\
\hline
\end{tabular}

Continued. 


\begin{tabular}{|c|c|c|}
\hline Study objective & Variable/data & $\begin{array}{l}\text { Data collection } \\
\text { method/participants }\end{array}$ \\
\hline & & $\begin{array}{l}\text { Net benefit } \\
=\text { Costs avoided } \\
+ \text { Increases in productivity } \\
\text { - Costs of the intervention }\end{array}$ \\
\hline \multirow[b]{3}{*}{$\begin{array}{l}\text { To determine the } \\
\text { implications for learning } \\
\text { from the research for } \\
\text { policy, programming and } \\
\text { scaling, and future } \\
\text { research }\end{array}$} & \multirow[b]{3}{*}{$\begin{array}{l}\text { Experience with workplace support, satisfaction and } \\
\text { potential areas for improvement }\end{array}$} & Qualitative \\
\hline & & $\begin{array}{l}\text { FGDs and IDIs with mothers } \\
\text { and men (fathers) }\end{array}$ \\
\hline & & $\begin{array}{l}\text { KIIs with health professionals } \\
\text { (doctors, nurses and } \\
\text { nutritionists), policy and } \\
\text { decision makers including } \\
\text { national health officials, county } \\
\text { health managers, plantation } \\
\text { managers and supervisors }\end{array}$ \\
\hline
\end{tabular}

Table 2: Quantitative and qualitative data analysis plan.

\begin{tabular}{|c|c|c|c|}
\hline Study objective & $\begin{array}{l}\text { Primary outcome } \\
\text { variable/independent } \\
\text { variable }\end{array}$ & Control variable & $\begin{array}{l}\text { Analysis } \\
\text { type }\end{array}$ \\
\hline $\begin{array}{l}\text { Establish the prevailing workplace } \\
\text { and living environment of } \\
\text { plantation workers with regards to } \\
\text { breastfeeding and infant feeding } \\
\text { practices, as well as child nutrition } \\
\text { and health care practices }\end{array}$ & $\begin{array}{l}\text { Factors that influence } \\
\text { breastfeeding and child care } \\
\text { practices }\end{array}$ & Not applicable & $\begin{array}{l}\text { Descriptive } \\
\text { (quantitative } \\
\text { ) } \\
\text { Thematic } \\
\text { (qualitative) }\end{array}$ \\
\hline $\begin{array}{l}\text { Assess the operational feasibility of } \\
\text { a model initiative on workplace } \\
\text { support for breastfeeding in a } \\
\text { Kenyan plantation }\end{array}$ & $\begin{array}{l}\text { Factors that influence } \\
\text { feasibility of a workplace } \\
\text { support model }\end{array}$ & Not applicable & $\begin{array}{l}\text { Descriptive } \\
\text { (quantitative } \\
\text { ) } \\
\text { Thematic } \\
\text { (qualitative) }\end{array}$ \\
\hline \multirow{4}{*}{$\begin{array}{l}\text { Determine the potential } \\
\text { effectiveness of the workplace } \\
\text { support initiative on breastfeeding } \\
\text { and child care practices }\end{array}$} & $\begin{array}{l}\text { - Breastfeeding practices } \\
\text { including initiation of } \\
\text { breastfeeding within one hour } \\
\text { of birth, EBF (for first } 6 \\
\text { months) and duration of } \\
\text { exclusive or any breastfeeding }\end{array}$ & \multirow{4}{*}{$\begin{array}{l}\text { Maternal socio-demographic } \\
\text { characteristics, food } \\
\text { security, health-seeking } \\
\text { behavior including antenatal } \\
\text { care, peri-natal and post- } \\
\text { natal care }\end{array}$} & \multirow{4}{*}{$\begin{array}{l}\text { Logistic } \\
\text { regression }\end{array}$} \\
\hline & $\begin{array}{l}\text { - Knowledge and attitude } \\
\text { levels on breastfeeding and } \\
\text { other infant feeding practices }\end{array}$ & & \\
\hline & $\begin{array}{l}\text { - Complementary feeding } \\
\text { practices, for example, } \\
\text { optimal timing of initiation of } \\
\text { complementary feeding and } \\
\text { minimum dietary diversity, } \\
\text { minimum meal frequency, and } \\
\text { minimum acceptable diet }\end{array}$ & & \\
\hline & $\begin{array}{l}\text { - Morbidity and care seeking } \\
\text { behavior }\end{array}$ & & \\
\hline $\begin{array}{l}\text { Determine the potential } \\
\text { effectiveness of the workplace }\end{array}$ & $\begin{array}{l}\text { Nutrition status ( child } \\
\text { underweight, stunting and } \\
\text { wasting) }\end{array}$ & $\begin{array}{l}\text { Maternal socio-demographic } \\
\text { characteristics, food } \\
\text { security, maternal socio- }\end{array}$ & $\begin{array}{l}\text { Logistic } \\
\text { regression }\end{array}$ \\
\hline
\end{tabular}

Continued. 


\begin{tabular}{|c|c|c|c|}
\hline Study objective & $\begin{array}{l}\text { Primary outcome } \\
\text { variable/independent } \\
\text { variable }\end{array}$ & Control variable & $\begin{array}{l}\text { Analysis } \\
\text { type }\end{array}$ \\
\hline $\begin{array}{l}\text { support model on child nutrition } \\
\text { and the health }\end{array}$ & Child morbidity & $\begin{array}{l}\text { demographic characteristics, } \\
\text { child morbidity, health- } \\
\text { seeking behavior including } \\
\text { antenatal care, peri-natal and } \\
\text { post-natal care, vaccination } \\
\text { status }\end{array}$ & \\
\hline $\begin{array}{l}\text { Determine the potential } \\
\text { effectiveness of the workplace } \\
\text { support initiative on work } \\
\text { participation and productivity of } \\
\text { female workers }\end{array}$ & $\begin{array}{l}\text { Productivity, absenteeism and } \\
\text { presenteeism }\end{array}$ & $\begin{array}{l}\text { Socio-demographic } \\
\text { characteristics }\end{array}$ & $\begin{array}{l}\text { Logistic } \\
\text { regression }\end{array}$ \\
\hline $\begin{array}{l}\text { Assess the cost-effectiveness of the } \\
\text { workplace intervention in terms of } \\
\text { health benefits for the employees } \\
\text { and their children. Furthermore, a } \\
\text { cost-benefit analysis will also be } \\
\text { done using the productivity } \\
\text { approach }\end{array}$ & Cost-effectiveness & Not applicable & $\begin{array}{l}\text { Cost- } \\
\text { effectiveness } \\
\text { analysis }\end{array}$ \\
\hline $\begin{array}{l}\text { Determine the implications for } \\
\text { learning from the research for } \\
\text { policy, programming and scaling, } \\
\text { and future research }\end{array}$ & $\begin{array}{l}\text { Implications for research, } \\
\text { policy and programming }\end{array}$ & Not applicable & $\begin{array}{l}\text { Qualitative } \\
\text { thematic } \\
\text { analysis }\end{array}$ \\
\hline
\end{tabular}

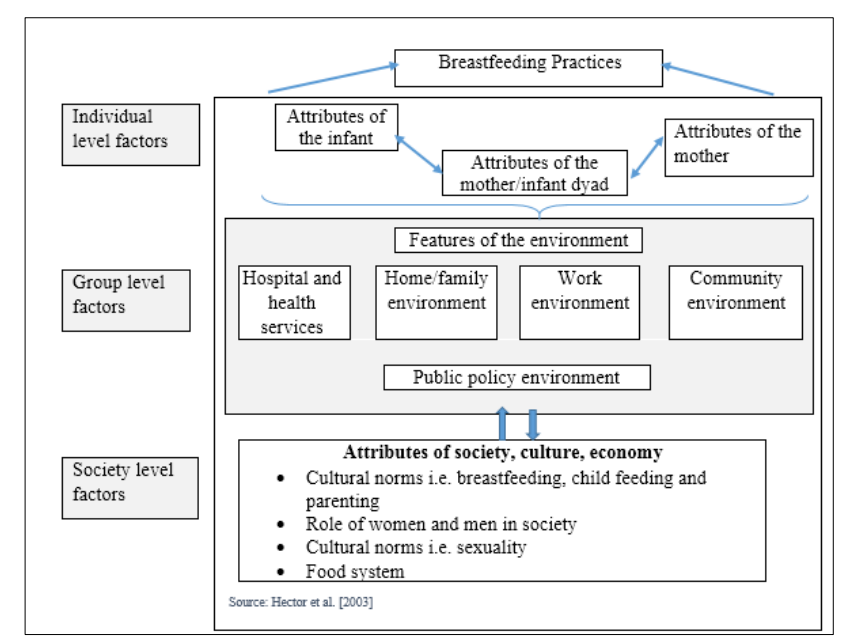

Figure 1: Conceptual framework of factors affecting breastfeeding practices.

\section{Cost-effectiveness analysis/modeling}

We will conduct both cost-effectiveness and cost-benefit analyses. For cost-benefit analysis, we will examine the employer's perspective and determine the return on investment by considering the costs to the business of implementing the intervention, and use the data captured in the surveys on worker absenteeism and productivity. Average differences in productivity and days in work will be estimated. The potential effect in the labor force such as retention of high performing staff, maintenance of a skilled workforce, improved morale, motivation and reputational benefit will be estimated from the quantitative interviews. Healthcare utilization will also be accounted for as this is provided by the employer.

For the cost-effectiveness analysis, we will examine the societal perspective and estimate the intervention's health cost-effectiveness in terms of cost per DALY. Health care costs, utilization and the DALYs associated with the observed changes in breastfeeding rates will be identified from the literature. Cost-effectiveness will be analyzed using a cost effective analysis (CEA) and modeling approach, involving: examination of the business case for the employer (employers' perspective) based on costs of implementing the intervention versus work participation and productivity; and examination of benefits to employees and case for policy through CEA and modeling health cost-effectiveness in terms of cost per DALY. ${ }^{33}$

\section{Community readiness scoring}

Community readiness scoring was conducted using the CRM guidelines. ${ }^{34}$ Scoring was done for each of the six dimensions on the tool including: community efforts (programs, activities, policies, etc.); community knowledge of efforts; leadership; community climate; knowledge about the issue; and, resources for prevention efforts (time, money, people, space, etc.) using a scoring sheet. The scoring was done by two trained research assistants working independently.

Any differences in scores was discussed and if agreement could not be reached, a third person independently scored the transcript to enable a majority agreed score to be generated. 


\section{Innovative participatory action research methods}

The produced videos and photos, and their accompanying stories will be displayed in exhibitions and used in photo books. These will play a key role in documenting experiences and perspectives of women and other community members as well as their views on improvement. This information will be useful in engaging stakeholders including the managers of the plantation, the Ministry of Health and UNICEF during the baseline and implementation phases of the initiative so as to minimize potential risks and maximize potential benefits.

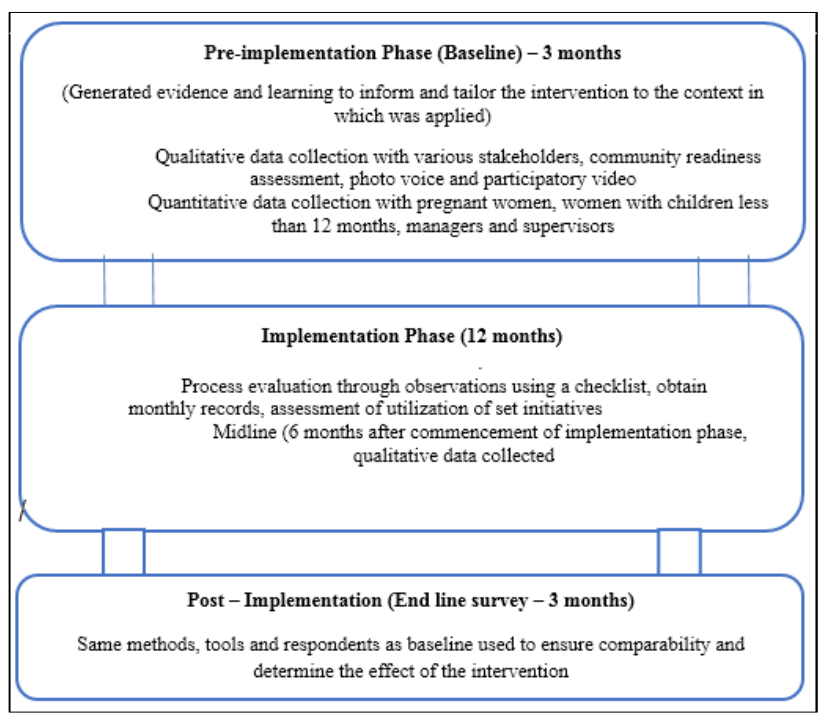

Figure 2: Schematic of the study design.

\section{Ethical approval and consent to participate}

Ethical approval has been granted by Amref Health Africa's Ethics and Scientific Review Committee (Amref ESRC) which is accredited by the Government of Kenya and has a Federal wide assurance number (FWA\#): FWA00018713. The study protocol number is P231/2016. The investigators will uphold the fundamental principles of ethics with regards to research on human subjects: i.e. justice, beneficence, non-malevolence and respect for human dignity outlined in the Helsinki Declaration (http://bit.ly/1dWyRro); and abide to relevant professional, ethical guidelines and codes of conduct in line with the OECD/DAC (2010) Quality Standards for Development of Evaluation. Written informed consent was obtained from all eligible participants in the interviews, photovoice and participatory videos before the engagement following full disclosure. Participants in photovoice were trained not to capture faces or any identifiable details in the photos and videos. Special consent was sought from participants of participatory videos as was not be possible to take anonymized videos. Permission was also be sought from relevant authorities including local authorities to allow entry into the community.

\section{DISCUSSION}

This paper describes the protocol for an evaluation and implementation research project that aimed to inform (with evidence) the design and implementation of a scalable model initiative on workplace support for breastfeeding in an agricultural setting in Kenya, and to explore its potential operational feasibility and potential effectiveness, as well as its cost-effectiveness.

Given the high rate of female labor participation in Kenya, $(62 \%)$, it is important to offer workplace support for this group. ${ }^{16}$ Several factors negatively impact breastfeeding rates including pressure to work long hours to make sufficient income, stressful lives, and inadequate facilities at work to express milk or breastfeed. Moreover, the threemonth maternity leave provided for in the employment guidelines is not sufficient to support EBF in the first six months. The fact that three quarters of the population in many African societies work informally, also means that maternity leave policies barely serve the majority of women, especially those in lower income groups. ${ }^{18}$ Furthermore, evidence has indicated that often, women in the informal sector are not allowed to bring their children to work. ${ }^{19}$ In a survey undertaken by Philips ${ }^{\circledR}$ in Kenya and Ghana, $52 \%$ of the women go back to work within three months after delivery, forced by the need to provide income for their families and driven by the fear of losing employment. ${ }^{17}$ This affects optimal breastfeeding and highlights the need for workplace support to enhance EBF and continued breastfeeding.

Literature reveals that interventions must be designed at multiple levels for successful implementation of workplace support for breastfeeding mothers. ${ }^{35}$ Collective efforts are required at the level of employee, employer, and workplace to promote a balance between breastfeeding and employment. ${ }^{36}$ Various interventions have been identified as necessary to support employed mothers for continued breastfeeding. They include: educating and guiding working mothers about breastfeeding; improving employers' awareness about breastfeeding; providing physical facilities for breastfeeding, expressing and storage at the workplace; providing flexibility in the work environment and paid maternity leave; and instituting mother and baby-friendly policies.

The role of breastfeeding support at workplaces in promoting EBF for the first six months of life cannot be underestimated. Benefits of EBF to the child and mother are irrefutable and therefore, providing a conducive work environment to ensure women can successfully combine breastfeeding and work is essential to child survival and wellbeing. To make this a reality, multiple level interventions and effective strategies need to be put in place. Findings from this study would inform the potential feasibility and potential effectiveness of a baby-friendly workplace support initiative in an agricultural setting, with the aim of improving child nutrition and health, and the initiative's cost-effectiveness. The study would be useful 
in informing, designing and implementing interventions in agricultural settings in Kenya. Further, it would also contribute to policy and practice in Kenya by informing the development of workplace support framework and guidelines. This intervention was therefore relevant and timely following the legislation passed by the government of Kenya for mandatory workplace support for breastfeeding as of September 2017.

\section{ACKNOWLEDGEMENTS}

Authors would like to acknowledge the Nutrition and Dietetic Unit of the Ministry of Health, Kenya including the Kericho County Health Management Team for their guidance in the design of the study and their continued support in the research. They are immensely grateful for the participation of the employer and employees of the agricultural setting where the intervention was implemented. They appreciate and thank their collaborators from the University of Warwick, Loughborough University, and McGill University for their technical expertise in the study design, implementation research, photovoice and participatory video techniques and taking the lead in the design of cost-effectiveness and community readiness assessments. They acknowledge the Kenya Private Sector Alliance, Kenya Federation of Employers, the Nutrition Information Working Group in Kenya among other stakeholders for their guidance in the study design. They are immensely grateful to the APHRC Research Staff for their technical support in the design of the study.

Funding: The study was funded from the Bill and Melinda Gates Foundation through UNICEF [contract number 43191524]

Conflict of interest: None declared

Ethical approval: The study was approved by Amref Health Africa's Ethics and Scientific Review Committee

\section{REFERENCES}

1. WHO. Breastfeeding. 2016. Available at: http://www.who.int/topics/breastfeeding/en/.

Accessed on: 28 September 2020.

2. Bahl RF, Kirkwood C, Edmond BR, Martines K, Bhandari J, Arthur PN. Infant feeding patterns and risks of death and hospitalization in the first half of infancy: multicentre cohort study. Bull World Health Organiz. 2005;83(6):418-26.

3. Diallo FB, Bell L, Moutquin JM, Garant MP. The effects of exclusive versus non-exclusive breastfeeding on specific infant morbidities in Conakry. Pan Afr Med J. 2009;2:2.

4. Victora CG, Bahl R, Barros AJD. Breastfeeding in the 21st century: epidemiology, mechanisms, and lifelong effect. Lancet. 2016;387(10017):475-90.

5. Kramer MS, Kakuma R. The optimal duration of exclusive breastfeeding: a systematic review. Adv Exp Med Biol. 2004;554:63-77.
6. WHO. Global strategy for infant and young child feeding. Singapore. 2003. Available at: https://www.who.int/nutrition/publications/infantfee ding/9241562218/en/. Accessed on: 02 August 2015.

7. UNICEF Statistics. 2014. Available at: Available at: http://www.data.unicef.org/index.php?section=uberr esources\&q=breastfeeding. Accessed on: 02 August 2015.

8. Republic of Kenya. National Nutrition Action plan 2012-2017. Calverton, Maryland: KNBS and ICF Macro, 2012. 2012.

9. Kenya National Bureau of Statistics (KNBS) and ICF Macro. Kenya Demographic and Health Survey 2014. Nairobi. 2015.

10. Chuang $\mathrm{CH}$, Chang PJ, Chen YC. Maternal return to work and breastfeeding: a population-based cohort study. Int J Nurs Studies. 2010;47(4):461-74.

11. Chuang $\mathrm{CH}$, Chang PJ, Hsieh WS. The combined effect of employment status and transcultural marriage on breast feeding: a population-based survey in Taiwan. Paediatr Perinatal Epidemiol. 2007;21(4):319-29.

12. Gielen AC, Faden RR, O'Campo P, Brown CH, Paige DM. Maternal employment during the early postpartum period: effects on initiation and continuation of breast-feeding. Pediatr. 1991;87(3):298-305.

13. Hawkins SS, Griffiths LJ, Dezateux C, Law C. Maternal employment and breast-feeding initiation: findings from the Millennium Cohort Study. Paediatr Perinatal Epidemiol. 2007;21(3):242-7.

14. Tsai SY. Impact of a Breastfeeding-Friendly Workplace on an Employed Mother's Intention to Continue Breastfeeding After Returning to Work. Breastfeeding Med. 2013;8(2):210-6.

15. Weber D, Janson A, Nolan M, Wen LM, Rissel C. Female employees' perceptions of organisational support for breastfeeding at work: findings from an Australian health service workplace. Int Breastfeeding J. 2011;6:19.

16. Labor force participation rate, female ( $\%$ of female population ages 15+). 2015. Available at: http://data.worldbank.org/indicator/SL.TLF.CACT. FE.ZS. Accessed on: 02 August 2015.

17. Philips Africa Innovation Hub. Breastfeeding in urban Africa:Towards empowering working mothers through innovation. 2015. Available at: http://newsghana.com.gh/wp-content/uploads/2015 /08/2015-August-Breastfeeding-in-Urban-AfricaPhilips-Report-FINAL.pdf. Accessed on: 02 August 2015.

18. Vanek J, Chen M, Heintz J, Hussmanns R. Statistics on the Informal Economy: Definitions, Regional Estimates \& Challenges.WIEGO Working Paper (Statistics) No 2. Cambridge, MA:: WIEGO. 2014. Available at: http://www.wiego.org. Accessed on: 02 August 2015.

19. Kimani-Murage EW, Wekesah F, Wanjohi M. Factors affecting actualisation of the WHO breastfeeding recommendations in urban poor 
settings in Kenya. Maternal Child Nutrition. 2015;11(3):314-32.

20. Ziraba AK, Madise N, Mills S, Kyobutungi C, Ezeh A. Maternal mortality in the informal settlements of Nairobi city: what do we know? Reproductive Health. 2009;6(1):6.

21. Ortiz J, McGilligan K, Kelly P. Duration of breast milk expression among working mothers enrolled in an employer-sponsored lactation program. Pediatric Nursing. 2004;30.

22. Wyatt SN. Challenges of the working breastfeeding mother. Workplace solutions. AAOHN J. 2002;50(2):61-6.

23. Mulama J. Africa, Development \& Aid, Headlines Development: Women Produce Most of the Tea Grown in Kenya. 2002. Available at: http://www.ipsnews.net/2002/10/developmentwomen-produce-most-of-the-tea-grown-in-kenya/. Accessed on: 14 November 2017.

24. Gitonga A. Flower firm garlands workers with rosy benefit. Standard digital. 2009.

25. Andrieu J, Chichester O, Meiers R, Poynton C, Shields L. Working Women and Health in East Africa's Agricultural Sector. BSR Working Paper. San Francisco.: BSR. 2014.

26. Hector D, King L, Webb K, Heywood P. Factors affecting breastfeeding practices: applying a conceptual framework. New South Wales Public Health Bull. 2005;16(3-4):52-5.

27. Wells KB. Treatment research at the crossroads: the scientific interface of clinical trials and effectiveness research. Am J Psychiatr. 1999;156(1):5-10.

28. Glasgow RE, Lichtenstein E, Marcus AC. Why don't we see more translation of health promotion research to practice? Rethinking the efficacy-to-effectiveness transition. Am J Public Health. 2003;93(8):1261-7.

29. OECD. DAC Guidelines and Reference Series: Quality Standards for Development Evaluation. 2010.
30. MoH-Kenya. Adolescent Sexual And Reproductive Health In Kericho County. 2009. Available at: https://www.afidep.org/download/Factsheet_Kericho-County-Final2.pdf. Accessed on: 10 November 2017.

31. Lohia N, Udipi SA. Infant and child feeding index reflects feeding practices, nutritional status of urban slum children. BMC Pediatrics. 2014;14(1):290.

32. WHO. Child Growth Standards based on length/height, weight and age. Acta paediatrica (Oslo, Norway : 1992). 2006;450:76-85.

33. Gold MR. Cost-effectiveness in health and medicine. Oxford university press; 1996.

34. Kansas CfCHaDUo. 2017. CRM Guidelines for Community Readiness Scoring. Available at: http://bit.ly/1QBtwTu; http://bit.ly/1VIK4xr). Accessed on: 15 October 2017.

35. Chen YC, Wu YC, Chie WC. Effects of work-related factors on the breastfeeding behavior of working mothers in a Taiwanese semiconductor manufacturer: a cross-sectional survey. BMC Public Health. 2006;6:160.

36. McIntyre E, Pisaniello D, Gun R, Sanders C, Frith D. Balancing breastfeeding and paid employment: a project targeting employers, women and workplaces. Health Promotion International. 2002;17(3):215-22.

Cite this article as: Kimani-Murage EW, Macharia TN, Kamande EW, Gatheru PM, Donfouet HPP, Alemu $\mathrm{T}$, et al. Assessment of the feasibility and potential effectiveness of a baby-friendly workplace support initiative in rural Kenya: a study protocol. Int J Clin Trials 2021;8(1):22-34. 